\title{
A Linguagem dos Bioblogs: contribuições da Linguística para o Ensino e Aprendizagem de Biologia
}

\section{The Language of Bioblogs: contribuitions of Linguistics to Biology Teaching and Learning}

\begin{abstract}
Resumo: A pesquisa objetivou entender se blogs de biologia podem ser considerados espaços de ensino-aprendizagem. Utilizou-se uma análise textual baseada no Paradigma Indiciário, que permitiu compreender aspectos essenciais da linguagem desses espaços virtuais, aspectos esses decisivos na construção de conhecimento, visto que este processo é mediado pela linguagem. Foi constatado que os blogs possuem quatro parâmetros principais influentes no processo de ensino-aprendizagem: uso de ferramentas linguísticas para facilitar transmissão de conteúdos; organização visual para concatenação de informações; zelo pela veracidade de informações transmitidas; possibilidade de comunicação entre leitores e autores. É demonstrada a validação dos blogs como espaços produtores de ensino/ aprendizagem, carentes de maior atenção e estudo pela academia.
\end{abstract}

Palavras-chave: Blogs. Aprendizagem Virtual. Ensino de Biologia.

\begin{abstract}
This research aimed to understand if biology blogs can be considered teaching-learning spaces. Using an analysis basead on the Indiciary Paradigm, it was possible to comprehend essential aspects of the language of these virtual spaces, aspects decisive in the construction of knowledge, as this process is mediated by language. We show that blogs have four main parameters that influence the teaching-learning process: use of linguistic tools to facilitate transmission of subjects; visual organization to concatenate informations; diligence of the veracity of transmited informations; possibility of communication between readers and authors. We demonstrate the validation of blogs as valid spaces of learning, spaces that require more attention and study by the academy.
\end{abstract}

Keywords: Blogs. Virtual Learning. Biology Teaching.

CARON, Monica Filomena; SALLES, Luis Francisco Prado Pinheiro Ferreira. A Linguagem dos Bioblogs: contribuições da linguística para o ensino e aprendizagem de Biologia. Informática na Educação: teoria e prática, Porto Alegre, v. 17, n. 2, p. 99-111, jul./dez. 2014.

\section{Monica Filomena Caron}

\author{
Luis Francisco Prado Pinheiro Salles \\ Universidade Federal de São Carlos
}

\section{Introdução}

A educação é sempre produto de um contexto histórico (TARDIF; LESSARD, 2005). Pensar a educação em uma sociedade objetivando entender como se dá o ensino/a aprendizagem nela, portanto, implica em entender o contexto sócio-econômico-político no qual essa sociedade se insere. A sociedade hodierna é caracterizada por uma grande informatização, decorrente da movimentação de grandes fluxos de informação pela internet. A educação é, inevitavelmente, perpassada por esse fenômeno. 
Essa crescente informatização dos meios de produção e comunicação do mundo atual criou um fenômeno conhecido por sociedade da informação, na qual o principal bem de consumo deixou de ser o produto fabril e passou a ser constituído pelos serviços, que por sua vez são produtos diretos da informação e do conhecimento (VIEIRA, 2005). Essa transformação, do principal produto a ser consumido pela sociedade, seria fruto da evolução tecnológica e da capacitação intelectual das pessoas (SILVA, 2009).

A circulação de informações na sociedade da informação ocorre, cada vez mais, através do ciberespaço, definido por Lévy (1999, p. 92) como "[...] o espaço de comunicação aberto pela interconexão mundial dos computadores e das memórias dos computadores". Sendo um espaço aberto de comunicação que pode ser acessado por pessoas de diferentes países e níveis sócio-econômicos e histórias de vida, que podem ser tanto leitores quanto autores de textos na internet, o ciberespaço consolida-se como uma mídia de transmissão que rompe com a lógica da mídia de massa, visto que essa simplesmente transmite informações, ao passo que aquela permite que o usuário faça parte do processo de comunicação, manipulando o meio e o conteúdo da informação. Desse modo, o ciberespaço é um espaço de comunicação que permite a rejeição de hierarquias da sociedade industrial centralizada, visto que agora "[...] ganha espaço o modelo de rede de organização e comunicação, que tem raízes na formação espontânea, igualitária e natural de grupos de pessoas de interesses semelhantes" (SILVA, 2009, p. 80).

Na sociedade da informação, a internet consolidou-se não só como uma ferramenta cada vez mais presente em várias atividades humanas, mas como um meio de comunicação relevante (senão o principal) da população mais jovem. Arruda (2009) avalia que o ciberespaço ocupa uma parte cada vez maior da vida dos estudantes, o que leva os professores a terem dificuldade em manter a relação docente-discente da maneira como ela é tradicionalmente conceituada: as limitações de espaço-tempo que antes se situavam na sala de aula já não são mais obstáculos ao aprendizado, devido principalmente ao advento da internet, que possibilita a tomada de uma quantidade infindável de informações de uma maneira muito rápida. Ainda, a recém-formada opinião sobre a postura do professor no contexto da vida do aluno imerso em um mundo profundamente tecnológico, a de que o professor deve se tornar um orientador do aluno na busca deste pelo conhecimento; não só é uma mudança da relação professor-aluno como uma "[...] ruptura com as formas anteriores de ensino e aprendizagem" (ARRUDA, 2009, p. 20).

Ainda tratando da inovação na maneira como se aprende dentro desse mundo tecnológico, o mundo virtual (ícones, hiperlinks e as produções de conhecimento livres e colaborativas da internet) exige e cria capacidades cognitivas diferentes daquelas que são formadas em sala de aula. As redes que formam as tecnologias de informação e comunicação (TICs) possuem uma lógica horizontal, sem hierarquias ou comandos centrais, o que faz com que elas tenham duas características: uma instabilidade que acarreta constantes mudanças; a possibilidade de qualquer pessoa fazer parte dessa rede, se manifestando e até aprendendo e ensinando através dela. Assim, o uso das TICs desenvolve em seus usuários uma lógica de raciocínio que não segue a lógica tradicional, na qual a escola possui referenciais de ensino baseados em padrões como "[...] programas calcados em lógicas lineares e a preocupação demasiada em possibilitar aos educandos o mero acesso a informações" (BO- 
NILLA, 2009, p. 33). No espaço virtual esses referencias já não são válidos, pois a estrutura em redes permite a troca de informações, experiências e opiniões, retirando o "[...] privilégio da posse do conhecimento [...] uma vez que o conhecimento foi gerado dentro da comunidade" (BONILLA, 2009, p. 30).

Ao fenômeno descrito soma-se mais um fator preponderante: as próprias formas de escrita e leitura da internet, o hipertexto. As páginas da internet possuem informações conectadas através de links, que possibilitam a leitura de um texto que remete a outros, ou a vídeos, imagens e sons que mantém ligação com o texto inicial. Essas conexões deixam dinâmica a busca por informações no meio virtual, de modo que elas se ligam em formas de redes, sendo acessadas muito mais rapidamente do que por meios impressos (LÉVY, 1999, KOMESU, 2005b). Essa característica da linguagem da internet acentua a quebra com a já citada lógica de raciocínio da escola tradicional.

Todas as considerações feitas anteriormente sobre a informatização da sociedade e da transmissão de informações fazem parte de uma discussão que deve incluir um estudo linguístico. Ainda que o estudo da linguagem esteja inserido desde o Ensino Básico, como notam Bagno e Rangel (2005), o ensino de língua no Brasil passa por um período de crise, que afeta o uso e aprendizado da mesma, e os alunos não desenvolvem uma capacidade plena de leitura e escrita. Dessa forma, os espaços virtuais podem ser um espaço de análise da percepção, do uso e da construção da linguagem por seus autores e leitores, e todos esses fatores são essenciais para os processos de ensino e aprendizagem de qualquer conteúdo.

O presente trabalho partiu de todas as questões levantadas anteriormente e objetivou analisar a transmissão de conhecimento, mais especificamente de biologia, dentro do espaço virtual. Devido à amplitude da internet, optou-se por fazer essa análise dentro de um canal de comunicação mais específico circulante nela: os blogs.

Em sua tese de doutorado, KOMESU (2005) define blogs como sendo:

[...] uma página web, composta de parágrafos dispostos em ordem cronológica (dos mais aos menos atuais colocados em circulação na rede), atualizada com freqüência pelo usuário. O dispositivo permite a qualquer usuário a produção de textos verbais (escritos) e não-verbais (com fotos, desenhos, animações, arquivos de som), a ação de copiar e colar um link e sua publicação na web, de maneira rápida e eficaz, às vezes, praticamente simultânea ao acontecimento que se pretende narrar. (KOMESU, 2005a, p. 99)

Devido à facilidade da criação de blogs (KOMESU, 2004), já que a hospedagem de blogs na internet é gratuita e não são necessários conhecimentos profundos de informática para criá-los, eles adquiriram, ao longo dos últimos anos, uma grande importância na transmissão de informações. O número de blogs existentes é grande e aumenta rapidamente (LEMOS, 2012, CATONE, 2010) e eles podem ser acessados por qualquer pessoa com conexão à internet.

Os assuntos tratados pelos blogueiros são muito variáveis: muitos blogs são páginas pessoais nas quais os autores descrevem fatos da sua vida pessoal e/ou cotidiana; outros são usados profissionalmente, como fonte de renda; alguns tratam de assuntos específicos e são comumente acessados por um público mais restrito, interessado no assunto. Há assuntos que costumam ter um restrito número de leitores, mas que acompanham com frequência e assiduidade as postagens. Dentro des- 
sa última categoria acreditamos estarem os blogs analisados nesse artigo.

Optou-se pelo estudo da linguagem desse meio visto que toda forma de construção de conhecimento é mediada pela linguagem, como afirma Colaço (2004, p. 339): "[...] no processo interativo e discursivo enraíza-se a essência e toda a base da construção compartilhada de conhecimento, que evidencia os processos de mediação da linguagem". Sendo assim, neste trabalho é realizada uma análise das formações discursivas dos blogs em língua portuguesa e inglesa: como elas se configuram, quais são suas legitimidades e quais são seus autores.

Uma dificuldade comum encontrada em estudantes com relação aos conteúdos das ciências biológicas é o entendimento da terminologia científica. Esta, apesar de ser uma ferramenta necessária para uma comunicação eficiente entre os profissionais da biologia, dificulta o aprendizado dos alunos, que não são familiarizados com o léxico científico (FERREIRA; SANTOS; OLIVEIRA, 2010). A análise dos aspectos linguísticos realizada nesse artigo levou em conta este fato, atentando para possíveis recursos que os autores poderiam utilizar para eliminar ou reduzir as dificuldades na transmissão de conteúdos da área.

\section{Metodologia}

\subsection{Constituição do Corpus ${ }^{1}$}

Foram estudados 10 blogs em língua portuguesa e língua inglesa. Na seleção foram esco-

\footnotetext{
${ }^{1}$ Segundo Charaudeau e Maingueneau (2004), corpus designa o conjunto de dados que servem de base para a descrição e análise de um fenômeno. Na verdade, aqui há uma questão relativa ao modo como se entende o fazer ciência sobre textos. Diferentemente de pesquisas quantitativas, a pesquisa qualitativa pretende investigar fenômenos multifacetados e não dados estatísticos e/ou evidências laboratoriais.
}

Ihidos blogs com o maior número de acessos encontrados, já que esses devem se constituir como as páginas mais influentes no processo de ensino e aprendizagem de biologia, pois atingem um maior número de pessoas. Para determinar se um blog se encaixava nesse parâmetro foram usadas duas técnicas: observação do contador de visitas da página ou sua presença no site ScienceBlogs.

O contador de visitas é um dispositivo fornecido por certos sites para outras páginas, que solicitam esse mecanismo para saber quantas pessoas já visitaram a página, ou quantos acessos ela recebe por hora, dentre outras informações quantitativas sobre o número de visitantes.

O site ScienceBlogs mantém uma rede de blogs em língua inglesa que tratam de diferentes áreas das ciências. Os blogs selecionados para fazerem parte dessa rede são escolhidos com base, segundo relato dos administradores do site, em suas características ligadas à originalidade, discernimento, talento, dedicação e o quanto eles contribuem para a discussão de diferentes tópicos das Ciências Exatas, da Natureza e Humanas (SCIENCEBLOGS, 2013). Há também o ScienceBlogs Brasil, uma página associada ao ScienceBlogs, que traz blogs de autores brasileiros, e em língua portuguesa. Os administradores do ScienceBlogs Brasil (Seed Media Group) afirmam que o objetivo da página é divulgar o pensamento científico, aproximando-o da sociedade em geral (SCIENCEBLOGS BRASIL, 2011). Ambas as páginas foram usadas como mecanismo de escolha de blogs para o presente trabalho, já que os blogs nelas encontrados são todos de grande repercussão, e assim se configuram como importantes fontes de transmissão de conhecimento. 


\subsection{Metodologia da Pesquisa}

A análise textual desenvolvida na pesquisa baseou-se no Paradigma Indiciário proposto por Carlo Ginzburg, brevemente descrita a seguir.

Segundo Ginzburg (1989, p. 152), o Paradigma Indiciário constitui "[...] a capacidade de, a partir de dados aparentemente negligenciáveis, remontar a uma realidade complexa não experimentável diretamente". Esse saber teria começado a se afirmar nas ciências humanas no final do século XIX, com a proposta do italiano Giovanni Morelli para distinção de obras de arte originais de suas cópias. Essa distinção era feita através do exame dos "[...] pormenores mais negligenciáveis [...] os lóbulos das orelhas, as unhas, as formas dos dedos [...]" (GINZBURG, 1989, p. 144). O psicanalista Sigmund Freud interessou-se pela proposta de Morelli, como aparece em seu ensaio $O$ Moisés de Michelangelo (FREUD, 1976, citado por GINZBURG, 1989, p. 147): "Creio que o seu método está estreitamente aparentado à técnica da psicanálise médica. Esta também tem por hábito penetrar em coisas concretas e ocultas através de elementos pouco notados $[\ldots]$.. Percebe-se que Freud, ao propor a psicanálise como uma análise do inconsciente a par- tir de minúcias ou características antes negligenciadas, baseia-se no que Ginzburg chama de Paradigma Indiciário. Além da psicanálise, também outras ciências humanas tomam esse mesmo método para efetuar raciocínios lógicos. Dentro dessas ciências estão: "[...] a história, a arqueologia, a geologia, a astronomia física e a palentologia [...]" (GINZBURG, 1989, p. 151), as ciências forenses e mesmo a medicina, que permite "[...] diagnosticar as doenças inacessíveis à observação direta na base de sintomas superficiais [...]" (GINZBURG, 1989, p.151).

Tendo em vista sua grande utilidade nas diferentes ciências humanas, adotou-se o Paradigma Indiciário como o instrumento de pesquisa linguística mais adequado para este trabalho, pois, como constata Duarte:

Já há algum tempo tem-se utilizado o Paradigma Indiciário em pesquisas linguísticas, pelo fato de que tal paradigma de investigação permite explicar ou, pelo menos, conjeturar sobre dados que por natureza são idiossincráticos e não se enquadram nos padrões de normalidade da língua. Tais dados são relevantes pela singularidade que os caracteriza, isto é, são exemplos interessantes e representativos de certos fenômenos linguísticos que permitem àqueles que os analisam descrever diferentes aspectos da linguagem (DUARTE, 1998, p. 63). 


\subsection{Resultados e Discussão}

A Tabela 1, a seguir, mostra os nomes dos blogs pesquisados e seus respectivos endereços virtuais.

\begin{tabular}{|l|l|}
\hline Blog & Endereço \\
\hline Diário de Biologia & http://diariodebiologia.com/ \\
\hline Biologia Evolutiva & http://biologiaevolutiva.wordpress.com/ \\
\hline Brontossauros em Meu Jardim & http://scienceblogs.com.br/brontossauros/ \\
\hline Rainha Vermelha & http://scienceblogs.com.br/rainha/ \\
\hline Discutindo Ecologia & http://scienceblogs.com.br/discutindoecologia/ \\
\hline A Crônica das Moscas & http://scienceblogs.com.br/cronicamoscas/ \\
\hline Você que é Biólogo... & http://scienceblogs.com.br/vqeb/ \\
\hline Marco Evolutivo & http://scienceblogs.com.br/marcoevolutivo/ \\
\hline Meio de Cultura & http://scienceblogs.com.br/meiodecultura/ \\
\hline RNAm & http://scienceblogs.com.br/rnam/ \\
\hline Jung's Biology Blog & http://jchoigt.wordpress.com/ \\
\hline College Biology Blog & http://collegebio.wordpress.com/ \\
\hline The Biology Blog & http://www.thebioblog.com/ \\
\hline Nothing In Biology Makes Sense & http://nothinginbiology.org/ \\
\hline ERV & http://scienceblogs.com/erv/ \\
\hline Greg Laden's Blog & http://scienceblogs.com/gregladen/ \\
\hline Life Lines & http://scienceblogs.com/lifelines/ \\
\hline We, beasties & http://scienceblogs.com/webeasties/ \\
\hline Page 3.14 & http://scienceblogs.com/seed/ \\
\hline Pharyngula & http://scienceblogs.com/pharyngula/ \\
\hline
\end{tabular}

TABELA 1 - Nomes dos Blogs Pesquisados e seus Respectivos Endereços Virtuais

FONTE: Elaborada pelos autores. 
De modo geral, a análise apontou para a existência de muitas semelhanças entre os blogs escritos em língua portuguesa e os produzidos em língua inglesa. Os autores são todos formados em biologia e têm pelo menos uma pós-graduação completa ou em andamento. Apesar de certos blogs tratarem somente de áreas específicas, como zoologia, microbiologia, evolução, alguns apresentam conteúdos mais gerais, não se restringindo a uma certa área. Entretanto, nota-se que a pós-graduação dos autores costuma direcionar os assuntos que serão abordados, sendo tratados mais assuntos que estejam dentro da área de experiência e interesse dos autores.

A variedade linguística predominantemente usada pelos blogueiros nem sempre segue a norma-padrão da língua culta: alguns autores utilizam-se de gírias ou até de certas abreviações do chamado internetês, como $v c$ ou $p q$, como, por exemplo, na postagem do blog Brontossauros em meu Jardim (2011) sobre uma matéria de revista tratando de um produto químico para perda de peso: "Porque há evidências de que a Victoza aumenta o risco de se ter pancreatite em 2.8 vezes, uma doença com sintomas bastante desagradáveis (que devem fazer vc emagrecer tb)" (HOTTA, 2011). Também, em algumas ocasiões, é possível encontrar erros de grafia, no uso de acentuação ou pontuação. Não podemos saber se o erro provém do fato de o autor ter errado a digitação do texto ou não ter seguido e atentado para a norma culta por desconhecimento da regra.

Quanto à estética de apresentação dos blogs, há uma grande variação, desde páginas com desenhos, muitas cores, planos de fundos com imagens e detalhes, até páginas mais simples, de plano de fundo branco e sem desenhos. Entretanto, todos os blogs analisados prezaram pela organização das postagens da página, organização esta que é feita de diferentes formas, dependendo do autor, sendo comum o arranjo das postagens por data ou assunto.

Uma característica de todos os blogs analisados foi a presença de hyperlinks - ícones que permitem ao leitor de uma página ser redirecionado à outras páginas da internet - nas postagens efetuadas pelos autores. A presença desses ícones determina uma maior amplitude no processo de aprendizagem, visto que o leitor terá acesso não só às informações da postagem do blog que lê, como também aos conhecimentos presentes nos hyperlinks, e assim a sua leitura terá uma maior quantidade de informações agregadas, provenientes de várias fontes que podem ser comparadas (KOMESU, 2005b, ORAVEC, 2002), estimulando o pensamento reflexivo (BRAGA, 2004). Os hyperlinks são importantes, na medida em que criam a possibilidade de digressão nos textos da internet e de intertextualidade.

Uma característica marcante de muitos blogs, tanto de língua portuguesa quanto de língua inglesa, é o uso da criatividade, especialmente na elaboração dos títulos das postagens. Esses títulos, muitas vezes de feição humorística, podem contribuir para chamar a atenção do leitor para a leitura do texto. Um exemplo é a postagem de título A Aranha Mais Nerd, sobre aranhas do gênero Portia no blog Rainha Vermelha. Ao longo do texto, o autor descreve estratégias altamente sofisticadas desses seres para caça, e no final do texto, o autor a chama de a aranha mais nerd, retomando o título da postagem². Outro exemplo é o texto "Scientists on brink of HIV cure Ugh.

\footnotetext{
2 Disponível em: <http://scienceblogs.com.br/rainha/2013/ 01/aranha-ner/> Acesso em: 13 fev. 2013.
} 
UUUUUUUUGH. *sigh*"/3. A postagem é uma crítica da autora a uma notícia de divulgação científica sobre uma nova técnica possível de ser usada para curar a Síndrome da Imunodeficiência Adquirida (AIDS). A autora discordou do modo como a notícia foi escrita, e usou de uma onomatopeia Ugh. UUUUUUUUGH e uma simbologia escrita que demonstra desprezo através de um suspiro *sigh* no título de seu texto, configurando uma proposta criativa e humorística de título, de forma a atrair a atenção do leitor para o tópico. Essa proposta de uso da criatividade, e em especial, de humor, presente nos textos dos blogs, consolida-se como um instrumento de ensino válido, pois como ressalta Askildson (2005, p. 49): "[...] humor remains an important instrument for the improvement of educational contexts in general, and language educational contexts in particular"4. Alguns blogs não apresentaram tais características, resumindo-se a páginas com uma conotação menos criativa, de caráter mais normativo e cujo estilo aproxima-se mais do texto do gênero científico, que obedece e atende às regras de normatização e padronização e preza pela ausência de estilo pessoal na construção do texto, com ênfase no conteúdo.

Outro aspecto marcante do corpus é a presença de textos que têm o intuito de ensinar ou divulgar uma informação específica de biologia contando uma história, que não raro é composta de acontecimentos reais da vida do autor. É frequente nessas postagens a mistura de gêneros de textos: os autores valem-se do texto científico, diário e crônica (estes com

\footnotetext{
3 "Cientistas à beira da cura para o HIV Ugh. UUUUUUUUGH. *sigh*" (tradução nossa). Disponível em: <http://scienceblogs.com/erv/2013/04/28/scientists-on-brink-of-hiv-cure-ugh-uuuuuuugh-sigh/> Acesso em: 25 mai. 2013. Do blog em língua inglesa: "ERV" (Endogenous Retrovirus, sigla inglesa para Retrovírus Endógeno).

${ }^{4} \mathrm{O}$ humor permanece como um importante instrumento para a melhoria de contextos educacionais em geral, e contextos educacionais linguísticos em particular.
}

caráter predominantemente humorístico). No texto Uma Revolução Infravermelha, do blog Brontossauros em Meu Jardim, o autor propõe-se a descrever vários aspectos do uso da fluorescência infravermelha no estudo de tecidos ao microscópio eletrônico, e uma dessas descobertas foi realizada por um cientista que deu uma palestra a qual o autor compareceu, como ele próprio relata: "Em 2004 tive a oportunidade de ver Roger Tsien falar em um curso de microscopia de fluorescência [...]. Foi lá que concluí que ele certamente ganharia um prêmio Nobel pelo seu trabalho, profecia que se concretizou no ano passado"s. Note-se que o trecho é marcadamente do gênero diário, e ao longo da postagem o autor utiliza-se do gênero científico para explicar suas descobertas. Já a crônica pode ser notada no trecho que segue, que teve como intuito divulgar a classificação dos três domínios de seres vivos feita por Carl Woese (presente no texto do blog A Crônica das Moscas:

O que é vida? vida é bactéria. Elas já estavam aqui, permaneceram, vão continuar até o Sol evaporar os últimos aceanos do nosso planeta e, aposto uma grana alta que até depois dessas transformações holocausticas que o mundo como o conhecemos irá atravessar, elas ainda vão estar dando as caras. (HOTTA, 2011)

Muitos dos blogs analisados disponibilizam, geralmente ao final das postagens, referências bibliográficas sobre o assunto discorrido, ou mesmo a(s) fonte(s) que serviu(ram) de base para o autor escrever seu texto - este último caso é mais frequente em postagens que tem o

\footnotetext{
(Disponível em: <www.carloshotta.com.br/brontossauros/2009/5/21/uma-revoluco-infravermelha.html> Acesso em: 04 abr. 2013).

Disponível em: <www.carloshotta.com.br/brontossauros/2009/5/21/uma-revolucao-infravermelha.html> Acesso em: 04 abr. 2013.
} 
intuito de explicar, analisar ou divulgar descobertas científicas publicadas em forma de artigo científico. Esse aspecto remete ao trabalho de Komesu (2010), que ao analisar a liberdade de expressão em blogs ressalta que um aspecto tido como essencial pelos blogueiros, quando estes estão disseminando informações, é a citação de fontes consideradas fidedignas, condicionando um instrumento institucional de validade das afirmações dos autores dos blogs.

Outro aspecto marcante em muitos blogs foi uso de imagens e vídeos. O uso de imagens é especialmente valorizado em certos blogs como um recurso didático, sendo apresentado, quase sempre, junto às postagens, como uma ferramenta de auxílio para a aprendizagem do leitor. Outras vezes, as postagens resumem-se à mostra de imagens com legendas explicativas, caracterizando postagens voltadas mais à divulgação de uma informação como curiosidade. Todavia, em todos os blogs há uso acentuado de imagens e estas estão presentes em textos explicativos e não raro em textos argumentativos, nos quais os autores propõem-se a explicar determinado tema através de uma argumentação mais longa do que a comumente encontrada em textos com figuras e/ou vídeos.

A observação e análise das respostas dos leitores aos conteúdos postados pelos autores nos blogs demonstrou um aspecto importante considerado por Oravec (2002) como a definição de um posicionamento crítico por parte dos leitores àquilo que se lê. A possibilidade de responder aos conteúdos lidos em blogs permite aos leitores (sejam eles estudantes ou simplesmente pessoas interessadas em certos conteúdos) desenvolver uma análise crítica, postulando suas próprias opiniões através da elaboração de argumentos bem construídos. Um exemplo disso é a resposta de um leitor ao tópico: "Snow, cold, influenza and colds -
Temperature and Infectious Disease"7, presente no blog We, Beasties ${ }^{8}$. Na página, o autor faz considerações sobre as razões do aumento de incidência de gripe e resfriados durante o inverno, citando as baixas temperaturas como imunossupressoras e o menor tempo de exposição aos raios solares, essenciais para produção de vitamina $D$, importante, por sua vez, para a regulação do sistema imunológico, como fatores que podem explicar esse aumento na ocorrência de gripes e resfriados. A resposta do leitor Patrick Garcia delineia ainda mais uma provável causa desse aumento, o resfriamento do muco nas paredes nasais humanas: "I know that mucus in the body dries up in the winter which is bad for the body because mucus traps bacteria $[\ldots]^{\prime \prime}$. Fica evidente o estímulo de raciocínio reflexivo e de posicionamento crítico através da emissão de respostas às postagens dos blogs evidenciado por Oravec (2002). Também é importante notar a importância dessas respostas como espaço de emissão de opiniões, de argumentação, de forma que os leitores ali podem desenvolver essas capacidades, e também a capacidade de considerar as opiniões alheias (MORTENSEN; WALKER, 2002, citados por LAMSHED; BERRY; ARMSTRONG, 2004). Não somente isso, o exemplo citado mostra também como as respostas de autores podem contribuir à adição

\footnotetext{
7 "Neve, frio, gripe e resfriados - Temperatura e Doenças Infecciosas" (tradução nossa).

${ }^{8}$ Esse nome não tem uma tradução específica; trata-se de um trocadilho com a expressão wee beasties, criada por um cientista, que significa minúsculos animais ou minúsculas bestas cuja melhor tradução seria nós, bestas, mas isso não seria totalmente correto porque isso seria we, beasts, sem contar que beasty, singular de beasties, seria algo como o diminutivo de beast. Então talvez a tradução mais adequada seja nós, pequenas bestas. Enfim, trata-se de um nome próprio, então não deve ser traduzido.

9 "Sei que muco no corpo seca no inverno, o que é ruim para o corpo porque o muco aprisiona bactérias [...]" (tradução nossa). Disponível em: <http://scienceblogs.com/webeasties/2013/02/08/snow-cold-influenza-and-colds-temperature-and-infectious-disease/\#comments > Acesso em: 24 de abr. 2013.
} 
de informações aos conteúdos dos blogs, aumentando ainda mais a quantidade de informações disponíveis nessas páginas.

Com relação à dificuldade de estudantes diante da terminologia científica da biologia, o que se verifica é que blogueiros, cujos textos sejam voltados a estudantes de ensino básico e/ou ao público em geral, tentam reduzir a distância entre o conhecimento dos leigos e a terminologia científica através de recursos como comparações, metáforas ou descrições de certos termos, como se verifica em um trecho da postagem sobre dentição no blog Diário de Biologia (2013): "A dentina não fica exposta, ela é coberta pelo esmalte, a camada dura, mais branquinha e brilhante que escovamos". Entretanto, os blogs voltados a um público-alvo mais específico, como biólogos graduados ou especialistas, não apresentam esses recursos, visto que os autores desses blogs parecem dialogar consideranndo um público-alvo que domina a terminologia científica utilizada no âmbito da biologia.

O autor do blog Biologia Evolutiva relata que é professor de Biologia no Ensino Médio, e que tomou a decisão de criar um blog sobre evolução depois de escrever um livro sobre a disciplina, visto que "[...] senti[u] a necessidade de criar um blog sobre evolução, onde eu pudesse escrever tantas e tantas ideias e análises que pensei em colocar no livro [...] em como muitas outras que nos surgem [...] ao ler um artigo, ao ver um documentário" (BIOLOGIA..., 2013). A fala do autor demonstra o que se tentou evidenciar neste trabalho de pesquisa: a importância do estudo dos blogs como ferramenta de ensino e aprendizagem, visto que o material e o espaço comumente usados como meios de estudo, o livro e a sala de aula, respectivamente, não são suficientes para armazenar uma quantidade de informações tão grande como a que é facilmente encontra- da hoje na internet. Os meios tradicionais de ensino já não dão conta de manter todas as discussões empreendidas na sociedade informatizada contemporânea, que é cada vez mais ampla, rápida e globalizada.

Nos blogs há os papeis de autor e leitor. O primeiro propõe a discussão acerca de um tema, e fornece informações e fontes sobre aquilo que está tratando. O segundo reflete sobre esse tema, e tem a possibilidade de opinar sobre o que leu. Não somente o leitor, como o autor, tem a possibilidade de conhecer novos assuntos e acrescentar informações às discussões dentro do blog, estabelecendo uma relação dialógica. O meio de comunicação, a internet, é baseado na linguagem escrita e imagética (áudio, visual e musical). Assim, é válido afirmar que os blogs são espaços de ensino e aprendizagem, tanto quanto a sala de aula ou quaisquer outros espaços de ensino.

\section{Conclusões}

A análise dos blogs realizada por este estudo permitiu entender quatro parâmetros essenciais dos blogs que influenciam na construção de conhecimento dentro destes espaços. O primeiro deles é o uso de ferramentas linguísticas para facilitar o entendimento dos conteúdos transmitidos nos blogs pelos leitores, predominando recursos de textos informais; variedade linguística fora da norma-padrão culta; uso de humor; escrita sobre conteúdos científicos a partir de situações cotidianas; uso de comparações, metáforas e explicações elaboradas para apresentação de termos técnico-científicos; uso de imagens e vídeos. O segundo deles relaciona-se a aspectos visuais e organizacionais dos blogs, importantes para a concatenação e rápida localização de diferentes fontes sobre os assuntos tratados: estética 
limpa; organização das postagens; e presença de hiperlinks. O terceiro é o cuidado em transmitir informações verídicas, evidenciado por blogs especializados em certos assuntos e pela presença de referências biblio e web gráficas nas postagens. $O$ quarto é a possibilidade de comunicação entre os leitores dentre si e entre eles e os autores, aspecto que permite debates, críticas e reflexões essenciais para a concretização da aprendizagem. Assim, fica evidenciada a necessidade de uma maior atenção da comunidade científica e de instituições de ensino para os blogs como espaços altamente eficientes de ensino e aprendizagem.

\section{Referências}

ARRUDA, E.P. Relações Entre Tecnologias Digitais e Educação: perspectivas para a compreensão da aprendizagem escolar contemporânea. In: FREITAS, M.T. de A. (Org.). Cibercultura e Formação de Professores. Belo Horizonte: Autêntica Ed., 2009. Cap. 1, p. 13-22.

ASKILDSON, L. Effects of humor in the language classroom: Humor as a pedagogical tool in theory and practice. Arizona Working Papers in SLAT, Tucson, AZ, v. 12, p. 45-61, 2005.

BAGNO, M.; RANGEL, E. de O. Tarefas da Educação Linguística no Brasil. Revista Brasileira de Linguística Aplicada, Belo Horizonte, v. 5, n. 1, p. 63-81, 2005.

BIOLOGIA Evolutiva [blog]. [2013?] Disponível em: <http://biologiaevolutiva.wordpress.com/about/> Acesso em: 06 nov. 2013.

BONILLA, M.H.S. Escola Aprendente: comunidade em fluxo. In: FREITAS, M.T. de A. (Org.). Cibercultura e Formação de Professores. Belo Horizonte: Autêntica Ed., 2009. Cap. 2, p. 23-40.

BRAGA, D.B. Linguagem Pedagógica e Materiais Para Aprendizagem Independente de Leitura na Web. In: COLLINS, H.; FERREIRA, A. Relatos de Experiência de Ensino e Aprendizagem de Línguas na Internet. Campinas: Mercado de Letras, 2004. P. 157-184.

CATONE, J. A look back at the last 5 years in blogging. 2010. Disponível em: <http://mashable. com/2010/08/03/last-5-years-blogging/> Acesso em: 18 set. 2012.

Charaudeau, P.; MAingueneaU, D. Dicionário de Análise do Discurso. Tradução: Fabiana Komesu. São Paulo: Contexto, 2004.

COLAÇO, V. de F.R. Processos Interacionais e a Construção do Conhecimento e Subjetividade de Crianças. Psicologia: reflexão e crítica, Porto Alegre, v. 17, n. 3, p. 333-340, 2004. 
DIÁRIO de Biologia [blog]. [2013?] Disponível em: <http://diariodebiologia.com/2011/08/9028/\#. Uh0_Uz-_j6M> Acesso em: 13 fev. 2013.

DUARTE, C. Uma Análise de Procedimentos de Leitura Baseada no Paradigma Indiciário. 1998. Tese (Mestrado em Linguística) - Instituto de Estudos da Linguagem, Universidade de Campinas, 1998, Campinas, BR-SP.

FERREIRA, L.P. da S.; SANTOS, C.C.C.; OLIVEIRA, E.G.M. de. Dificuldades no Manejo Oral e Escrito dos Termos Técnico-científicos de Biologia e/ou Ciências. In: COLÓQUIO INTERNACIONAL EDUCAÇÃO E CONTEMPORANEIDADE, 4., 2010, Laranjeiras, SE. [Trabalhos Apresentados]. Laranjeiras: UFS, 2010. Disponível em: <http://www.educonufs.com.br/IVcoloquio/cdcoloquio/eixo_05/E5-27.pdf> Acesso em: 3 nov. 2011.

GINZBURG, C. Sinais: raízes de um paradigma indiciário. In: Mitos, Emblemas, Sinais: morfologia e história. Trad. Frederico Carotti. 2. reimpr. São Paulo: Companhia das Letras, 1989. P. 143-179.

HOTTA, C. A VEJA e os Perigos do Victoza. In: HOTTA, C. Brontossauros em Meu Jardim [blog]. São Paulo: [s.n.], 2011. Disponível em: <http://www.carloshotta.com.br/brontossauros/2011/9/8/a-veja-e-os-perigos-do-victoza.html> Acesso em: 11 jan. 2013.

KOMESU, F.C. Blogs e as Práticas de Escrita Sobre Si na Internet. In: MARCUSCHI, L.A.; XAVIER, A.C. (Org.). Hipertexto e Gêneros Digitais: novas formas de construção do sentido. Rio de Janeiro: Lucerna, 2004. P.110-119.

KOMESU, F.C. Entre o Público e o Privado: um jogo enunciativo na constituição do escrevente de blogs da internet. 2005a. Tese (Doutorado em Linguística) - Instituto de Estudos da Linguagem, Universidade de Campinas, 2005, Campinas, BR-SP.

KOMESU, F.C. Pensar em Hipertexto. In: ARAÚJO, J.C.; BIASI-RODRIGUES, B. (Org.). Interação na Internet: novas formas de usar a linguagem. Rio de Janeiro: Lucerna, 2005b. P. 87-108.

KOMESU, F.C. Espaços e Fronteiras da "Liberdade de Expressão" em Blogs na Internet. Trabalhos em Linguística Aplicada, Campinas, v. 49, n. 2, p. 343-357, 2010.

LAMSHED, R.; BERRY, M.; ARMSTRONG, L. Blogs as electronic learning journals. E-Journal of Instructional Science and Technology, Toowoomba, AU, v. 7, n. 1, 2004. Disponível em: <researchbank. rmit.edu.au/view/rmit:3125> Acesso em: 18 set. 2012. 
LEMOS, M. Seu Blog Não é NADA na Blogosfera. In: FERRAMENTAS Blog. [S.I.], 2012. Disponível em: <http://www.ferramentasblog.com/2012/04/seu-blog-nao-e-nada-na-blogosfera.html> Acesso em: 18 set. 2012.

LÉVY, P. Cibercultura. Tradução: Carlos I. da Costa. São Paulo: Ed. 34, 1999.

ORAVEC, J.A. Bookmarking the world: Weblog applications in education. Journal of Adolescent and Adult Literacy, Newark, v. 45, n. 7, p. 616-621, 2002.

SCIENCEBLOGS. About ScienceBlogs. [S.I.]: Seed Media Group, 2013. Disponível em: <http://scienceblogs.com/about/> Acesso em: 20 nov. 2012.

SCIENCEBLOGS BRASIL. Sobre ScienceBlogs Brasil. [S.I.]: Seed Media Group, 2011. Disponível em: <http://scienceblogs.com.br/sobre/> Acesso em: 20 nov. 2012.

SILVA, M. Infoexclusão e Analfabetismo Digital: desafios para a educação na sociedade da informação e na cibercultura. In: FREITAS, M.T. de A. (Org.). Cibercultura e Formação de Professores. Belo Horizonte: Autêntica Ed., 2009. Cap. 5, p. 75-86.

TARDIF, M.; LESSARD, C. O Trabalho Docente: elementos para uma teoria da docência como profissão de interações humanas. Petrópolis: Ed. Vozes, 2005.

VIEIRA, M.A.N. Educação e Sociedade da Informação: uma perspectiva crítica sobre as TIC num contexto escolar. 2005. Dissertação (Mestrado em Educação) - Instituto de Educação, Universidade do Minho, 2005, Braga, PT.

Submetido para avaliação em 03 de abril de 2014.

Aprovado para publicação em 20 de setembro de 2014.

Monica Filomena Caron: Universidade Federal de São Carlos - Campus Sorocaba - Sorocaba - SP - Brasil. Email: monicacaron@yahoo.com.br

Luis Francisco Prado Pinheiro Ferreira Salles: Universidade Federal de São Carlos - Campus Sorocaba - Sorocaba - SP - Brasil. - Email: luisfrancisco_eus@hotmail.com 